\title{
Janus in the viscous field: A reflexive account on researching homelessness through institutionalised spaces of care
}

\section{Panos Bourlessas}

Department of Culture, Politics and Society, University of Turin, Turin, Italy

\section{Correspondence}

Panos Bourlessas

Email: panagiotis.bourlessas@unito.it

\section{Funding information}

There are no funders to report for this submission.
Given the scarcity of methodological reflections by geographers studying homelessness, and drawing from ethnographic research in Athens, this paper provides an empirical reflexive account of the complexities of practising homelessness research through "spaces of care." Emphasising the institutional nature of these spaces, it highlights the role of institutions, such as NGOs and public authorities, in shaping certain local contexts for geographic research. Precisely, the circulation of specific homeless-related discourses throughout spaces of care shapes the "viscous field" of institutions, wherein research moves become difficult and subject positionings are set a priori. Therein, the two-faced figure of Janus becomes the metaphor for the geographer in the viscous field, who embodies simultaneously two faces-roles: of researcher and volunteer. Afterwards, a focus on bodies highlights the emotional and performative aspects of the encounters with research participants. Eventually, four-plus-one ethical pro-positions for practising geographic research on homelessness are given in place of conclusions. Overall, the paper is an empirical contribution to institutional geographies, their methodologies, and the difficulties, complexities, and negotiations for researchers-volunteers. The "trouble of institutions" may also be a methodological trouble for geography practitioners in research sites such as spaces of care, where researchers-volunteers, participants, and institutions become entangled with one another.

\section{K E Y W O R D S}

Athens, ethics, ethnography, homelessness, institutional geographies, reflexivity

\section{1 | INTRODUCTION: REFLEXIVITY, INSTITUTIONS, AND HOMELESSNESS RESEARCH}

Reflexivity is a well-established conceptual tool in geographic research. This "deconstructive exercise for locating the intersections of author, text, and world, and for penetrating the representational exercise itself" (Macbeth, 2001, p. 35) expands to two different yet interconnected and essential ingredients of knowledge production: positionality and ethics. On the one hand, through reflexivity "[facets] of the self ... are articulated as 'positions' in a multidimensional geography of power relations" (Rose, 1997, p. 308) and, on the other, researchers can develop "a means of addressing and responding to ethical concerns [emerging] in the research" (Guillemin \& Gillam, 2004, p. 276). Given the scarcity of methodological reflections by geographers studying homelessness (but see Cloke et al., 2000; DeVerteuil, 2004; Lancione \& Rosa, 2017), this paper utilises reflexivity to provide an empirical account of (some of) the methodological complexities of practising homelessness research through "spaces of care." 
The account draws from my seven-month multi-sited ethnography on the homeless geographies of Athens, Greece, conducted at a day centre, a night shelter, and two hostels for homeless people. Whereas these spaces can be conceptualised as what geographers have called "spaces of care" for the homeless (Conradson, 2003a, 2003b; Johnsen et al., 2005), I suggest that the focus here be that these spaces are institutional. Precisely, shaped and managed by either public or non-governmental institutions, spaces of care generate certain institutional homeless geographies throughout the city. ${ }^{1}$ Subject to funding schemes and regulations, enabling specific ethoses, discourses, and practices, and performing spatially a new poverty management in Athens (Arapoglou \& Gounis, 2017), they altogether shape the city's "institutionalized context of care" (Tronto, 2010, p. 160). Therefore, the term "institution" here is used neither in the "classic" Goffmanian sense of the "total institution" nor in any other Goffman-inspired sense, such as that of the "reinventive institution" (Scott, 2010). Instead, by referring to spaces of care as "institutional spaces of care," I attempt to highlight the role of institutions, namely NGOs and public authorities, in shaping certain local contexts for geographic research and the respective accounts produced. It is these institutional contexts - along with their im/possibilities - that give meaning to my reflexive exercise.

Geographers have stressed the particularities of "institutional ethnography," calling for a wider deployment of this method across the discipline (Billo \& Mountz, 2015). In research with vulnerable groups especially, institutions are often pivotal either as research sites or as gatekeepers or as both; they become inevitably entangled with researchers and participants (von Benzon \& van Blerk, 2017), and "complicate the microgeography of the research encounter" (von Benzon, 2017, p. 1054). Regarding homelessness research specifically, DeVerteuil (2004) provides valuable and place-specific reflections on how a homeless shelter might become a "research setting" full of barriers, opportunities, negotiations, and shifting positionalities. Despite DeVerteuil's call to pay careful attention to how research settings affect geographic fieldwork, it remains strikingly unaddressed in homelessness research.

Thus, this paper is a response to this very call: an empirically rich account of the complexities, shifting positionalities, contradictions, embodiments, and, eventually, inescapable ethical extensions of geographical research in institutionalised spaces of care. Its grounded evidence contributes to broader debates on the volunteer-researcher entanglements geographers are called to deal with, linking these debates and evidence specifically to literature on spaces of care. Finally, by emphasising the role of institutions, I aspire to show that the "trouble of institutions" that, for Philo and Parr (2019), critical scholars must attend to, may also be a methodological trouble, while, by bringing empirical evidence from outside the Anglophone world and developing ethical extensions from this very evidence, I firmly seek to contribute to Area's future agenda (Kraftl et al., 2018).

The following section illustrates how certain institution-generated discourses shape what is termed the "viscous field" of spaces of care, where research moves are limited and subject positionings set a priori. Section 3 likens the researcher in the viscous field to the two-faced figure of Janus, embodying simultaneously two faces-roles: of researcher and volunteer. Section 4 centres on bodies to highlight the emotional and performative aspects of Janus' encounters with research participants. The final section provides four-plus-one ethical pro-positions for practising geographic research on homelessness.

\section{2 | THE "VISCOUS FIELD” OF SPACES OF CARE}

In the field, I find myself struggling to move in a space where a powerful discourse has become solidified almost material - saturating most research areas. Research moves feel difficult, subject positions already set. As if a thick liquid flowing all over and filling up the field, this discursive mass makes the research space viscous. (Field notes, 22 May 2017)

During fieldwork, a specific discourse was generated by the institutions managing the spaces of care: "There is always something psychopathological to end up here," the head of the night shelter once explained. Circulating the homeless "idiom of pathology" (Hopper, 1991, p. 783), numerous similar claims diffused a "homeless psychopathology" discourse throughout the spaces of care. In its wide circulation, then, the discourse saturated these spaces to such an extent that the research field was experienced as "viscous," as the above excerpt describes: viscous in a sense that certain positionings of the research practice, namely, those of the researched primarily and of the researcher consequently, were, in different yet mutual manners, fixed a priori.

The homeless psychopathology is not just an immaterial condition. Rather, by medicalising homeless subjects (LyonCallo, 2000), it solidifies psychic problems through embodiment - the component -pathology - fixing them within the homeless bodies and fixing these bodies within the field. Yet, this fixing-within and fixing-of homeless bodies is relational. 
In its diffusion, the mobilised discourse gradually constructed the binary "psychopathological"/"normal." "Don't worry," the hostel's psychologist reassured me, "we will find some normal [research participants]." Opposite the homeless "psychopathology" was (set and performed) our - the employees,' volunteers,' researcher's - "normality." Opposite the homeless: us, me. The widespread instrumentalisation, circulation, and assembling of such claims and practices by the institutions gradually established the field's viscosity.

Having been attributed the positioning of the "psychopathological" and the "normal," the homeless and the researcher respectively were immersed in a thick discursive mass where their in-between distance was hard to traverse. Therein, the homeless person I would encounter was not simply an "Other"; they were a "psychopathologic Other." The psychopathology discourse was hence adding another layer of othering onto, and therefore distancing from, homeless subjects. Effectively, whereas my aim had principally been to approach the person and not the "Other," to the extent this is possible (see Lancione \& Rosa, 2017), the coming-together of the researching and researched bodies was difficult in the viscous field. For the therein positioning was fixed in advance and the discursive mass would make it hard for the bodies to move and finally encounter one another. If the field is "a region undergoing continual processes of construction" (Driver as cited in Powell, 2002, p. 262), the institutional discourses had constructed my field as a viscous such region.

The field's viscosity became more evident in the case of the hostels, where managing institutions did not permit me any direct involvement in their practices. In those spaces of care, the institutions themselves would first contact potential research participants; then, I myself would encounter the ones who had accepted to participate. Although this process allowed me to contact homeless people I would not have been able to contact otherwise, it raised serious methodological and ethical issues (Williams, 2017; also Moran, 2013 on the "partial sample"). By having "the right to choose" research participants, institutions had also the power to perform their own evaluations, discourses, and categorisations, often aligned to the psychopathology discourse: "I have tried to select them in a way that all categories are represented [...] And imagine that the ones you met are the most normal ones here!" The viscous field was becoming even more viscous when I realised that my research practice was giving institutions the power to reproduce stereotypes and shape homeless subjectivities in negative and patronising manners. This was the moment when I considered it appropriate to quit the research conducted through this channel and proceed with spaces of care where direct involvement was possible. Volunteering has been a central research practice to negotiate the field's viscosity.

\section{3 | JANUS' TWO FACES: EMBODYING THE RESEARCHER-VOLUNTEER}

Being a volunteer at the day centre and night shelter allowed unmediated contact with homeless people and, therefore, I myself was able to approach research participants based on the research criteria, appropriate timing, emotions, and, above all, on familiarity with homeless people, attained through daily contact and mutual exchanges. In these areas of the viscous field, I was thus not only a researcher; I was also a volunteer. And this duality further perplexed my positionality and research practice.

The intersections of different roles, whether as researcher, volunteer, or practitioner, may have complicating effects on geographic fieldwork (Bachmann, 2011; Garthwaite, 2016; Williams, 2016). Specifically regarding researching and volunteering in welfare spaces, Williams (2017) coins the term "mixed loyalties" to refer to situations "where the researcher, in performing their role as volunteer ..., is required to follow particular procedures that may contradict their own personal ethics" (p. 1024). For the purposes of this paper, this section exemplifies the experienced "mixed loyalties" deploying metaphorically the two-faced figure of Janus, as the result of two different, often contradictory but omnipresent, embodied and interrelated positionings of contradictory directions: an internal, own-decided positioning as human geographer and researcher, willing to conduct ethical, critical, theoretically informed, and methodologically sound field research with homeless people; and an external, institutionally imposed positioning as a volunteer, expected to align to and represent the institutions, respect their principles, follow their practices, and adhere to their discourses. Immersed in the viscous field, Janus' double positioning further illustrates the methodological complexities of institutional spaces of care, concurrently suggesting that viscosity can be negotiated and somehow traversed.

\section{1 | Janus' volunteer face}

"Volunteering is a participatory research practice that enables the researcher to actively contribute to constituting and reproducing an organisation" (Williams, 2016, p. 2). In the case of my field's institutionalised spaces, it was this "constituting and reproducing" the institutions that complicated research positionings, and contributed to the field's viscosity. Precisely, it involved actions that opposed my own values; for instance, the punitive practice of not allowing the homeless to use the 
day centre's facilities if they arrived more than half an hour after the appointed time. Often aligned to institutional ethoses of service provision (Cloke et al., 2007), volunteering meant compromising with responsibilisation rhetorics, philanthropic discourses of who deserves help or not, and therapeutic actions with no systemic effect for the person in need. Above all, volunteering imposed distances between myself and the homeless subjects I was trying to encounter, amplifying thus the field's viscosity: "Don't talk with them that much!" Both at the day centre and night shelter, I was asked by employees to sustain distances, avoid close contacts, and not "create expectations," although the nature of these expectations remained undefined.

Dealing with the externally imposed volunteer's role has not been effortless, for it involved practices that marked my body in specific ways and performed the role in physical manners. Precisely, my involvement in the day centre presupposed a seven-hour training course, when, together with other volunteers, I was introduced to the organisation's principles through painting, writing, and interacting while I was positioned specifically in the organisation: as volunteer. Such bodily practices rendered the role bodily engaged. Similarly, I had to sign both at the beginning and the end of my shift, being thus further subjectified as volunteer; "For volunteers [signing] is mandatory but for [paid staff] not. It's the only way to check you," a social worker explained, slightly grinning. If geographical practice "is mediated by the way we sense ourselves in relation to institutions" (Catungal, 2017, p. 12), doing research and volunteering perplexed my "reflexive sense" of my research practice within the contexts of institutionalised spaces of care.

\section{2 | Janus' researcher face}

The inevitable embodiment of the volunteer called for a necessary emphasis on the Janus' face of the researcher as a way to negotiate the imposed positioning. Choosing specific positions during shifts at the day centre and night shelter, which would allow unmediated and possibly unsurveilled contact with homeless people, was a first step to this end. Nevertheless, it soon became evident that marking clearly my own contour as a researcher, hence different from the other volunteers and employees, had to be a continuous and situated practice if I wanted to proceed with my research in ethical manners. This contour was becoming gradually bolder by reminding homeless people, but often staff members too, that I was in that position for research purposes and, therefore, I was not representing any institution. Or, in practical terms, by giving someone a second soap or razor undercover, something against the rules, I was marking my position differently; I was not only a volunteer, I was also a committed researcher able to act. And as the research was evolving, it was research participants themselves who gradually reinforced my researcher's contour through our mutual contacts, in which my desired positioning was becoming increasingly clearer and more recognised.

As a result of the two different forces forging Janus, the external and the internal, and the often embodied "divergent responsibilities" (von Benzon \& van Blerk, 2017, p. 901), my positionality was experienced as fragile; every time the side of the volunteer was becoming too dominant, negotiations were necessary in order to balance it and redefine my positionality reinforcing the researcher's side. Yet, the aim was never to eliminate the volunteer's side but, rather, to balance it with that of the researcher in methodologically productive manners. Janus does not claim, therefore, a strict separation between "volunteer" and "researcher" as there exists no clear in-between boundary (Garthwaite, 2016). There have been only instants when the boundary felt clear before becoming indistinct again.

Overall, in a context of limited resources and budget cuts, affecting the ways care is performed, institutions themselves become troubled (Disney \& Schliehe, 2019) or vulnerable (von Benzon \& van Blerk, 2017). Janus' dual positionality ought to be viewed in relation to this too, perhaps contributing to the institutional trouble and vulnerability and adding ethical implications of a "mutual dependence." Whereas, on the one hand, I would depend on institutions as fertile research sites and gatekeepers, on the other, institutions, depending increasingly on the volunteers' labour, needed my contribution in the spaces of care as, for instance, shifts at the day centre and night shelter would partially depend on my availability. This mutual dependence raised further ethical questions in the field and the practising of fieldwork.

\section{4 | ENCOUNTERING THE HOMELESS: BODIES, EMOTIONS, PERFORMANCES}

If bodies, space, and knowledge co-constitute each other (Longhurst et al., 2008; Wainwright et al., 2018), this is also the case in the viscous field. In this section, encounters with homeless research participants in institutionalised spaces of care illustrate how the field's viscosity can be negotiated and eventually traversed through the emotional and performative aspects of the therein situated bodies, the latter being involved in a distance-proximity interplay. 


\section{1 | The emotional}

Countless "emotional moments" (Catungal, 2017) have filled my encounters with research participants. Interviews involved uncomfortable narrations of difficult experiences, mostly related to pathways to homelessness and also to everyday survival. Such narrations brought tears sometimes. And pauses. Pauses gave space for emotions to emerge: empathy, sadness, fear of possible reactions, anger, but also hollowness for a seemingly unimportant research practice. These were ingredients of the inescapable "labour pains" (Melrose, 2002), which affected positionalities and blurred the researcher-researched boundary, with empathy, above all, shaping the "common ground of shared emotion" (Evans, 2012, p. 3) and positioning the researching and researched bodies closer in the viscous field, at least momentarily.

Silence - the "sound of pauses" - was adding a great deal to shared emotional moments (see Ng, 2017). The silence that followed the description of one's first nights on the street, of a serious accident or decisive human loss, left me emotionally suspended in an uncomfortably silent waiting: of a response, awaited by both sides, mine and the person's in front of me. Silence revealed also the entanglements of emotions with ethics, and defined the immediate methodological moves. Was it ethical to proceed with questions when the research participant was emotionally vulnerable in their silence? And what if, besides the visible distress, there were veiled in silence "hundreds of [other] invisible impacts amongst networked actors" (Cloke et al., 2000, p. 151) that would make my research harmful? Every time I decided to break the silence and suggest ending the interview, the response was a clear will to go on. "[Silence] Now that I am telling you these things ... [Silence] As if they are being unlocked ... [Silence] opening up inside me [Silence]," a homeless man said, and wished to go on.

\subsection{The performative}

Bodily performative aspects highlight how positionalities in the viscous field, however to a certain degree set a priori, remain subject to change during research. Situated in spaces of care, the researching and researched bodies are entangled with non-human elements, such as the spaces' materiality (Sheehan, 2011; also Widdowfield, 2000). In one of the hostels, interviews were conducted in a separate office. The white walls, white furniture, and white lights would make the encounter feel too formal, sanitised, excessively institutionalised. By inscribing physical positionings, the room's materiality performed specific research positionalities: I would sit on the office chair behind the desk and participants would sit on a common, smaller chair in front of the desk. This all performed a "professional atmosphere," putting the researcher and researched in a hierarchical distance: the "expert" would wait "in his place" for the "subject of study" to arrive, be studied, and leave. Next, please! The bodily postures of some participants also expressed this positionality: inward, reserved, and self-protective - and so were indeed many of those interviews. My efforts to negotiate positionalities through different physical positionings - for example, by waiting for the research participant standing, rather than already sat, and letting them choose their place - were not successful; they would always choose the same chair, putting me in the place of the "professional," "protected" behind the desk.

Bodily performances may also dissolve "established," seemingly more fixed, positionalities in the viscous field. One day, due to lack of personnel, I had to conduct (the obligatory) body control ${ }^{2}$ at the night shelter's entrance on a research companion. Controlling the man radically shook the proximate positionalities that were shaped during months of mutual contact, casting the two sides away from one another again, back into the viscous field. Although he did not seem to bother at all (it was his routine, anyway), I experienced this bodily practice as threatening the existing positionalities, performing exaggeratedly visible power relations. One had the power on the body of the other and hence bodies were performed as distant from one another, albeit the control's paradoxical physical closeness.

On another day, I had an appointment with a different research companion in order to visit a public service together. Coming out from the metro station to meet him, I automatically removed my headphones and sunglasses; this was a usual tactic of mine during fieldwork and while being in the neighbourhoods of my research. In my view, such visible objects could perform an emphasised social distance in my encounters with homeless people. Of course, there is something of an ostrich mentality in this, as clothes have the same effect, but the fact that those elements were additive and easily removable made them feel more powerful to me. "Hey, you are tanned! You were on holidays?!," he said when he saw me. That time, it was my skin to shake established positionalities. We were both reminded of the in-between social difference and distance: one had been on holidays, the other not - for obvious reasons.

Nevertheless, bodily performances can be utilised purposefully in order to negotiate the field's institutional viscosity and perform proximity. Sharing a portion of rice at the soup kitchen has been critical in this direction. The food's shared materiality and the practice of eating from the same plate challenged my personal limits as far as cleanliness and taste are 
concerned, and positioned the researching and researched bodies closer to one another (Longhurst et al., 2008). Tasting the food in spaces of care has always been a bodily, sensory practice of understanding research participants and their (material) geographies, and an explicit act of performed proximity towards a material "relational baseline" (Jordan, 2002, p. 102). Other kinds of physical contact would strengthen proximate positionalities: touching a used towel without gloves performed a personal crossing of boundaries of hygiene and self-protection and challenged my position as a "detached" researcher. Such deeds would often happen, consciously aiming to achieve proximity with research participants despite the distances imposed by institutions, as well as an embodied engagement with research spaces and subjectivities.

\section{5 | IN PLACE OF CONCLUSIONS: ETHICAL PRO-POSITIONS FOR GEOGRAPHICAL RESEARCH PRACTICE WITH HOMELESS PEOPLE}

This paper provides a highly empirical reflexive contribution to institutional geographies and their methods. The trouble of institutions may also be a methodological trouble for geographers in research sites such as spaces of care for homeless people, where researchers-volunteers, participants, and institutions are entangled with one another. The methodological trouble of institutions stresses that research practice might contribute to the troubling nature of institutions. Considering the multiple ways which volunteers perform and reproduce institutional ethoses (Cloke et al., 2007), we need to reflect on how and to what extent geography Januses perform such ethoses as researchers-volunteers in institutionalised spaces. It is via grounded examples of the researcher-volunteer's mixed loyalties and divergent responsibilities it provides that this paper seeks to contribute to methodological debates in Geography, linking specifically to spaces of care. Utilising reflexivity, geographers can uncover the impact of institutions not only on research practice but also on the lives of people who depend on these spaces, people often in extremely vulnerable positions. Most importantly though, through reflexivity geographers ought to take "moral responsibility for [the] difference [between the researcher and the participant]" (Kobayashi, 2003, p. 348). Realising this very responsibility thus, in place of conclusions this closing section presents four-plus-one ethical pro-positions for practising geographic research with homeless people in institutionalised spaces of care, illustrating empirically how ethics in homelessness research might be "exhausted at the moment of one-to-one encounter" (Gounis, 1996, p. 115; Cloke et al., 2000) - when such encounters are finally achieved in the viscous field.

The first pro-position is to embody an active researcher role that makes meaningful use of their privileged positioning in order to affect positionalities in ways beneficial for research participants. "Give him chickpeas!," an employee ordered, whispering in my ear. On the other side of the counter, a homeless man was waiting for his lunch. Knowing that there was a variety of food available, I found it ethical from my side to gently ignore the employee's order and give the homeless person the right to choose: "Would you prefer rice, chickpeas, or lentils?." Through my own agency, the homeless person gained his agency by having a choice in his lunch - "Rice!" A relational ethical agency (Whatmore, 1997) had been for a moment achieved in the viscous field and the institutional power over a homeless subjectivity subverted (DeVerteuil, 2004, p. 377). When becoming tactical, such concrete fieldwork actions, as exemplified by the Janus analogy, expand towards the practising of critical ethnography (Madison, 2005), because they might actively combat the punitive practices care is often exercised through.

The second pro-position concerns this very subjectivity that many times seemed to be ignored, even eliminated, by the managing institutions. A characteristic shared by my research companions has been a desire to emphasise their individuality, attempting to position themselves outside of any homogenised "homeless" category. "I am not representative of the group, have nothing to add to your study"; or "my case is very different than the rest, will not help you to generalise"; similar reactions to my invitations for research involvement were common. Such desired positionings demanded a respect for individual homeless subjectivities, and their reinforcement throughout the whole research practice: from approaching the participant to the writing and communication of research outputs. The pro-position is ethical for two reasons: first, it is attentive to not reproduce stereotypes of "the homeless" (Paradis, 2000) and second, it exposes the institutions as powerful actors (Crang \& Cook, 2007, p. 28) by opposing their tendency to reproduce homogenised homeless subjectivities.

The third pro-position concerns the recognition of the researcher's positionality as subject to emotions and bodily performances, and hence open to interpersonal exchanges that may be positively transformative for participants (Ng, 2017). The practice of offering me a coffee has been a widespread homeless tactic to switch positionalities: "Next time, I will offer you one. To show you that $I$ am able to offer too!," one said after our interview. Although to accept a coffee from a person in extreme economic conditions would go against my morality, it proved ethical with respect to the homeless person's subjectivity and desire to position themselves as (what is often perceived to be) "normal." Practices of offering and gift exchange may be pivotal to shaping reciprocal research relations and help researchers to challenge positions of disempowerment, especially in viscous research fields. 
The fourth pro-position relates to the expectations inherent to the practising of ethnographic research, particularly with vulnerable groups. "... So that you can also help me, if possible," a woman said after the interview, asking me for a favour regarding some bureaucratic issues (also DeVerteuil, 2004). My simultaneous presence in various spaces of care built an image of someone with connections in the local welfare system, thus reinforcing expectations. Some of them could be met; many others could not. Expectations can be met through a constant giving-back of various, more or less silent, forms, which help negotiate the viscous field and its positionings: by maintaining contact with research companions after the fieldwork's closing; sharing information that has been gathered during research and that can be critical for homeless survival; discussing research results; opening up the therapeutic avenues of interviews, allowing the participants to indicate themselves the research directions; and sharing time and space together in order to advocate for them or provide types of assistance.

Finally, I would like to close by underlining that ethical geographical research that critically addresses social inequality, with its inexhaustible ethical pro-positions, ought to be traversed by a continuous memory, or the researcher's conscious effort to not forget the broad social change s/he is committed to and that reflexivity should be attuned to (Kobayashi, 2003). The below excerpt from my field notes describes such fears of forgetting - and the constant need to combat them:

After some time in the viscous field, I feel I'm getting used to these people's and spaces' condition. This getting-used, however developing inevitably through the field's everyday frictions and however closer it brings me to participants, should be combatted with a continuous memory throughout the entire research practice: to not forget the so much needed social change. (Field notes, 13 April 2017)

\section{ACKNOWLEDGEMENTS}

My gratitude goes to the homeless women and men who participated in my $\mathrm{PhD}$ research and provoked reflections that go far, far beyond methodologies. Access to the spaces of care mentioned in this article would not have been possible without the collaboration of people at the City of Athens Homeless Shelter (Department of Social Services), as well as at the NGOs Praksis and Médecins du Monde Greece. Last but not least, I would like to thank the Area Editors as well as the two anonymous Reviewers for their constructive criticism on my work.

\section{DATA AVAILABILITY STATEMENT}

For reasons of research ethics, data are not to be shared.

\section{ORCID}

Panos Bourlessas (D) https://orcid.org/0000-0003-1679-192X

\section{ENDNOTES}

${ }^{1}$ For an overview of Athens' archipelago of provision and care, its spatialities, and logics (with a special focus on the night shelter), see Bourlessas (2018).

${ }^{2}$ For "security reasons," all shelter users undergo body control before entering the shelter every day because certain objects are not permitted (e.g., knives, alcohol). The control also includes the opening of personal handbags and backpacks.

\section{REFERENCES}

Arapoglou, V. P., \& Gounis, K. (2017). Contested landscapes of poverty and homelessness in Southern Europe. Reflections from Athens. Cham, Switzerland: Palgrave Mcmillan.

Bachmann, V. (2011). Participating and observing: Positionality and fieldwork relations during Kenya's post-election crisis. Area, 43, $362-368$. https://doi.org/10.1111/j.1475-4762.2010.00985.x

Billo, E., \& Mountz, A. (2015). For institutional ethnography: Geographical approaches to institutions and the everyday. Progress in Human Geography, 40, 199-220. https://doi.org/10.1177/0309132515572269

Bourlessas, P. (2018). 'These people should not rest': Mobilities and frictions of the homeless geographies in Athens city centre. Mobilities, 13, 746-760. https://doi.org/10.1080/17450101.2018.1464544 
Catungal, J. P. (2017). Feeling bodies of knowledge: Situating knowledge production through felt embeddedness. Tijdschrift Voor Economische En Sociale Geografie, 108, 1-13, https://doi.org/10.1111/tesg.12229

Cloke, P., Cooke, P., Cursons, J., Milbourne, P., \& Widdowfield, R. (2000). Ethics, reflexivity and research: Encounters with homeless people. Ethics, Place \& Environment, 3, 133-154. https://doi.org/10.1080/713665889

Cloke, P., Johnsen, S., \& May, J. (2007). Ethical citizenship? Volunteers and the ethics of providing services for homeless people. Geoforum, 38, 1089-1101. https://doi.org/10.1016/j.geoforum.2006.07.005

Conradson, D. (2003a). Geographies of care: Spaces, practices, experiences. Social \& Cultural Geography, 4, 451-454. https://doi.org/10.1080/ 1464936032000137894

Conradson, D. (2003b). Spaces of care in the city: The place of a community drop-in centre. Social \& Cultural Geography, 4, 507-525. https:// doi.org/10.1080/1464936032000137939

Crang, M., \& Cook, I. (2007). Doing ethnographies. London, UK: Sage.

DeVerteuil, G. (2004). Systematic inquiry into barriers to researcher access: Evidence from a homeless shelter. The Professional Geographer, 56, 372-380. https://doi.org/10.1111/j.0033-0124.2004.05603006.x

Disney, T., \& Schliehe, A. (2019). Troubling institutions. Area, 51, 194-199. https://doi.org/10.1111/area.12501

Evans, M. (2012). Feeling my way: Emotions and empathy in geographic research with fathers in Valparaíso, Chile. Area, 44, 503-509. https:// doi.org/10.1111/j.1475-4762.2012.01104.x

Garthwaite, K. (2016). The perfect fit? Being both volunteer and ethnographer in a UK foodbank. Journal of Organizational Ethnography, 5, 60-71. https://doi.org/10.1108/JOE-01-2015-0009

Gounis, K. (1996). Urban marginality and ethnographic practice: On the ethics of fieldwork. City \& Society, 8, 108-118. https://doi.org/10.1525/c iso.1996.8.1.108

Guillemin, M., \& Gillam, L. (2004). Ethics, reflexivity, and "ethically important moments" in research. Qualitative Inquiry, 10, $261-280$. https://doi.org/10.1177/1077800403262360

Hopper, K. (1991). Homelessness old and new: The matter of definition. Housing Policy Debate, 2, 755-813. https://doi.org/10.1080/10511482. 1991.9521072

Johnsen, S., Cloke, P., \& May, J. (2005). Day centres for homeless people: Spaces of care or fear? Social \& Cultural Geography, 6, 787-811. https://doi.org/10.1080/14649360500353004

Jordan, S. A. (2002). Ethnographic encounters: The processes of cultural translation. Language and Intercultural Communication, 2 , 96-110. https://doi.org/10.1080/14708470208668079

Kobayashi, A. (2003). GPC ten years on: Is self-reflexivity enough? Gender, Place and Culture, 10, 345-349. https://doi.org/10.1080/ 0966369032000153313

Kraftl, P., Datta, K., Bryant, R., \& Nash, F. (2018). Fifty years of Area: Taking stock, looking forward. Area, 50, 434-439. https://doi.org/10. 1111/area.12500

Lancione, M., \& Rosa, E. (2017). Going in, out, through: A dialogue around long skirts, fried chips, frozen shacks and the makeshifts of ethnography. City, 21, 135-150. https://doi.org/10.1080/13604813.2017.1353335

Longhurst, R., Ho, E., \& Johnston, L. (2008). Using 'the body' as an 'instrument of research': Kimch'i and pavlova. Area, 40, 208-217. https:// doi.org/10.1111/j.1475-4762.2008.00805.x

Lyon-Callo, V. (2000). Medicalizing homelessness: The production of self-blame and self-governing within homeless shelters. Medical Anthropology Quarterly, 14, 328-345. https://doi.org/10.1525/maq.2000.14.3.328

Macbeth, D. (2001). On "Reflexivity" in Qualitative Research: Two Readings, and a Third. Qualitative Inquiry, 7, 35-68. https://doi.org/10.1177/ 107780040100700103

Madison, D. S. (2005). Critical ethnography: Method, ethics, and performance. Thousand Oaks, CA: Sage.

Melrose, M. (2002). Labour pains: Some considerations on the difficulties of researching juvenile prostitution. International Journal of Social Research Methodology, 5, 333-351. https://doi.org/10.1080/13645570110045963

Moran, D. (2013). Between outside and inside? Prison visiting rooms as liminal carceral spaces. GeoJournal, 78, 339-351. https://doi.org/10. 1007/s10708-011-9442-6

Ng, I. (2017). When [inter]personal becomes transformational: [Re-]examining life course-related emotions in PhD research. Area, 49, $409-414$. https://doi.org/10.1111/area.12325

Paradis, E. K. (2000). Feminist and community psychology ethics in research with homeless women. American Journal of Community Psychology, 28, 839-858. https://doi.org/10.1023/A:1005115901078

Philo, C., \& Parr, H. (2019). Staying with the trouble of institutions. Area, 51, 241-248. https://doi.org/10.1111/area.12531

Powell, R. C. (2002). The Sirens' voices? Field practices and dialogue in geography. Area, 34, 261-272. https://doi.org/10.1111/1475-4762.00080

Rose, G. (1997). Situating knowledges: Positionality, reflexivities and other tactics. Progress in Human Geography, 21, 305-320. https://doi.org/ $10.1191 / 030913297673302122$

Scott, S. (2010). Revisiting the total institution: Performative regulation in the reinventive institution. Sociology, 44, 213-231. https://doi.org/10. $1177 / 0038038509357198$

Sheehan, R. (2011). Actor-network theory as a reflexive tool: (inter)personal relations and relationships in the research process. Area, 43, 336342. https://doi.org/10.1111/j.1475-4762.2011.01000.x

Tronto, J. C. (2010). Creating caring institutions: Politics, plurality, and purpose. Ethics and Social Welfare, 4, 158-171. https://doi.org/10.1080/ 17496535.2010 .484259 
von Benzon, N., \& van Blerk, L. (2017). Research relationships and responsibilities: 'Doing' research with 'vulnerable' participants: introduction to the special edition. Social \& Cultural Geography, 18, 895-905. https://doi.org/10.1080/14649365.2017.1346199.

von Benzon, N. (2017). Confessions of an inadequate researcher: Space and supervision in research with learning disabled children. Social \& Cultural Geography, 18, 1039-1058. https://doi.org/10.1080/14649365.2016.1257148

Wainwright, E., Marandet, E., \& Rizvi, S. (2018). The body-space relations of research (ed) on bodies: The experiences of becoming participant researchers. Area, 50, 283-290. https://doi.org/10.1111/area.12367.

Whatmore, S. (1997). Dissecting the autonomous self: Hybrid cartographies for a relational ethics. Environment and Planning D: Society and Space, 15, 37-53. https://doi.org/10.1068/d150037

Widdowfield, R. (2000). The place of emotions in academic research. Area, 32, 199-208. https://doi.org/10.1111/j.1475-4762.2000.tb00130.x

Williams, A. P. J. W. (2017). Residential ethnography, mixed loyalties, and religious power: Ethical dilemmas in faith-based addiction treatment. Social \& Cultural Geography, 18, 1016-1038. https://doi.org/10.1080/14649365.2016.1247194

Williams, M. J. (2016). Justice and care in the city: Uncovering everyday practices through research volunteering. Area, 48, 513-520. https://doi. org/10.1111/area.12278

How to cite this article: Bourlessas P. Janus in the viscous field: A reflexive account on researching homelessness through institutionalised spaces of care. Area. 2019;00:1-9. https://doi.org/10.1111/area.12592 